\title{
CONGRESS ANNOUNCEMENT
}

\section{Congress Announcement}

(C) Springer-Verlag 2011

\section{Announcement and call for papers: SIMBIO-M 2011Congress Announcement}

International conference on SIMulation technologies in BIO-Sciences and Multiphysics June 20-22, 2011 Marseille, France

Call for papers can be downloaded at:

http://www.simbio-m.com/upload/Simbio2011_call_for_ papers.pdf

Abstracts submission deadline: March 7, 2011. Author notification: March 30, 2011. Papers submission deadline: April 30, 2011

The conference, endorsed by the ESB and the International Society of Multiphysics, is organised jointly by CADLM, IFSTTAR (formerly INRETS-LCPC) and the University of the Mediterrannee. The objective of the conference is to share and explore findings on numerical analysis techniques and mathematical modelling tools in various fields of Biosciences and Multiphysics. Academic and industrial presentations will address advancements in the following subject areas:

- Biomechanics

- Biomaterials

- Biomedical

Conference Website:

http://www.simbio-m.com

The SimBio-M organisation committee:

Prof. Kambiz Kayvantash, CADLM

Dr. Pierre-Jean Arnoux, IFSTTAR/Univmed-LBA

Dr. Michel Behr, IFSTTAR/Univmed-LBA Dr. Lionel

Thollon, IFSTTAR/Univmed-LBA

Contact: info@SimBio-M.com
2011 International Conference on Biomedical Engineering and Biotechnology (BEB)

2011生物医学工程与生物技术国际会议

Call for Papers

Oct. 28-30, 2011 Shanghai, China

http://www.engii.org/cet2011/beb2011.aspx

The 2011 International Conference on Biomedical Engineering and Biotechnology (BEB2011) will be held in Shanghai/China, Oct. 28-30, 2011, BEB is part of World Congress on Engineering and Technology (CET) which will take place in Shanghai China. The CET is composed of several conferences on the frontier topics in the engineering and technological subjects.

The CET conference proceedings will be published by IEEE, and the accepted papers will be indexed by $\mathrm{Ei}$ Compendex and ISTP.

IEEE 会议列表查询链接:(IEEE Conference Calender) http://www.engii.org/cet2011/NewsContent.aspx?newsID= 527

Paper Submission Deadline: April 30, 2011

Acceptance Notification: June 15, 2011

For more information, please contact:

Email: beb@engii.org

QQ: 58329403

QQ group: 133861010133861899 